\title{
Mechanical Properties of Bis-GMA/HEMA Resin Composite with Addition of Silicon Dioxide Nanoparticles
}

\author{
GABI TOPOR ${ }^{1}$, KAMEL EARAR ${ }^{1}$, ION CIUCA ${ }^{2}$, SORIN BERBECE ${ }^{1}$, \\ VICTORITA STEFANESCU ${ }^{1}$, ADRIAN BEZNEA ${ }^{1}$, CAMELIA ANA GRIGORE ${ }^{1}$, \\ MARIUS MARIS ${ }^{*}$, , SILVIA FOTEA ${ }^{1}$, CRISTIAN ONISOR ${ }^{1}$, RAMONA FEIER ${ }^{4}$, \\ CRISTINA MARINA IORDACHE ${ }^{5}$ GABRIELA GURAU ${ }^{1}$ \\ ${ }^{1}$ Dunarea de Jos University of Galati, Medicine and Pharmacy Faculty, 47 Domneasca Str., 800008, Galati, Romania \\ 2University Politehnica of Bucharest, 313 Splaiul Independentei, 060042, Bucharest, Romania \\ ${ }^{3}$ Titu Maiorescu University, Dental Medicine Faculty, 67A Gheorghe Petrascu Str., Bucharest, Romania \\ 4"Dimitrie Cantemir" University, Medicine Faculty, 3-5 Bodoni Sandor Str., 540545, Targu-Mures, Romania \\ ${ }^{5}$ "Grigore T. Popa" University of Medicine and Pharmacy, Faculty of Dental Medecine, 16 Universitatii Str., 700115, Iasi, \\ Romania
}

Abstract: The study of the mechanical behavior of materials intended for dental restorations is of crucial importance in the production of a finished product. In the present work, two resins were used for the material matrix, Bisphenol A diglycidyl methacrylate (Bis-GMA), hydroxyethylmethacrylate (HEMA) and a nanofiller $\left(\mathrm{SiO}_{2}\right)$. This study focuses on the influence of nanoparticle size (30, 50, 100 and 150 $\mathrm{nm}$ ) on the mechanical properties (flexural strenght and modulus, compression strenght and modulus and work of fracture) of the manufactured composite materials. The results showed improvements in the mechanical integrity of the samples, but differed depending on the size of the nanoparticles added. These differences are closely related to the active surface of the nanoparticles, leading to differences in fillerresin matrix compatibility.

Keywords: resin, Bis-GMA, HEMA, $\mathrm{SiO}_{2}$ nanoparticles

\section{Introduction}

Since ancient times, man has made a case study regarding the choice of materials for operative dentistry. Through trial and error along centuries of testing, researchers have never stopped developing new materials and techniques in order to prevent tooth structure loss, tooth wear or dental trauma. Currently the range of materials existing in this crucial area for society is larger than ever, and this trend seems to be in perpetual consolidation. An important role in the properties of biomaterials for the adhesion of biological cells is played by the composition of the material used and its charge [1 - 3], as well as by the affinity for water and surface roughness [4].

These biomaterials are subjected to physical and biological study, and the level of interaction with the human body is analyzed [5,6]. The basic requirements of biomaterials are mechanical characteristics, biocompatibility [7] and resistance to corrosion in body fluids and tissues [8]. Biocompatibility is the ability of the substance to interact with fluids and tissues of the body without causing undesirable harm to the body, such as toxicity and irritant effects, inflammatory and allergic reactions $[9,10]$.

In the production of novel biomaterials for dentistry applications, biocompatibility and biodegradability are considered main characteristics [11].

In addition, using inorganic nanofillers to improve the polymer matrix properties is a widely used technique to achieve improved performance [12]. Commonly used additives in the preparation of composite materials that are often processed with silane coupling agents are silica nanoparticle [13, 14].

G. Canché-Escamilla et al. studied the incorporation of nanoparticles with silica and PMMA through a polymerization process used as dental biomaterials. They observed that the use of hybrid filler nanoparticles allowed to incorporate a larger amount of inorganic filler. In this case, the hybrid nanoparticles did not show agglomerations of material, obtaining a uniform distribution [11]. 
Dental implants are obtained through various techniques that involve refining and mixing monomers, such as dimethacrylate triethylene glycol (TEGDMA), bisphenol A diglycidyl methacrylate (Bis-GMA), bisphenol A ethoxylated dimethacrylate (Bis-EMA) and dimethacrylate urethane [15]. Contraction, viscosity, and reactivity are directly determined by the composition of the dental resin. The mechanical properties and the absorption of water differs based on the method the biomaterial is obtained, but also on the nature of components [16].

Monomers used in the matrix of composite materials for dental purposes are divided into two broad categories: strongly viscous monomers, such as Bis-GMA, urethane dimethacrylate (UDMA); and diluent monomers, such as hydroxyethylmethacrylate (HEMA), TEGDMA, etc. [17-19]. Depending on the polymerization of the monomers, composite materials have various physical, chemical properties and clinical performance [20,21]. The biomaterials obtained were studied by the photo-differential scanning calorimetry (DSC) system for the reactivity of monomeric molecules and the dependence of the conversion of the double bond on the structure of the monomer. They observed that UDMA resins were significantly more reactive than Bis-GMA resins [22].

The global growth in tolerance to antibiotics contributes to the use of new infection prevention methods, and the use of metal oxides may be an interesting method for the production of antimicrobial biomaterials, since they have a significant antibacterial effect [23].

Coupling agents, like vinyltriethoxysilane and methacryloxypropyl-trimethoxysilane, increase the adherence between the resin and the surface of the filler particles. To reinforce the bond to the interface, modifications to the surface of the filler particles were also carried out (e.g., roughening and aggregation of the particles, resulting in mechanical retention).

Nanoparticles have been available for some time, but the early ones, formed agglomerations during the production process, thus limiting their use for dental composites. Subsequent research has led to the possibility of particle separation, generating a uniform dispersion offering the possibility to be incorporated into composites.

Liu et al. has studied the influence of $\mathrm{SiO}_{2}$ nanoparticle concentration in the poly(Bis-GMA)-grafted silanized hydroxyapatite whisker (PGSHW) [24]. Light permeability and filler packing density were enhanced through the incorporation of $\mathrm{s}^{-\mathrm{SiO}_{2}}$ nanoparticles in PGSHW (mass ratio 2:4), which effectively improved water sorption and solubility of the biomaterial. Physical and mechanical properties as well as in vitro bioactivity were significantly improved by the obtained $\mathrm{PGSHW} / \mathrm{s}-\mathrm{SiO}_{2}$ [24] .The objective of this work was to observe the effect of 4 nanoparticle dimensions on the Bis-GMA/ HEMA resins, which from the knowledge acquired by the authors in this study field, it represents a novelty. Based on the obtained composites, several mechanical properties were analyzed.

\section{Materials and methods}

\subsection{Materials}

For the composite materials, Bisphenol A diglycidyl methacrylate (Bis-GMA) was used as main monomer and hydroxyethylmethacrylate (HEMA) was the co-monomer. As initiator and co-initiator, camphorquinone and dimethyl aminoethyl methacrylate were added to the mixture. The $\mathrm{SiO}_{2}$ nanoparticles with 30, 50, 100 and $150 \mathrm{~nm}$ dimension were used as composite fillers. All substances were purchased also from Sigma-Aldrich.

Mixtures of $60 \%$ Bis-GMA with 30\% HEMA were prepared under mechanical stirring. A concentration of $9 \mathrm{wt} . \% \mathrm{SiO}_{2}$ was added to the pure monomers and the monomer mixtures.

The composites of Bis-GMA/HEMA were produced by the following process: the monomers were mixed with camphorquinone and dimethyl aminoethyl methacrylate, both of which amounted to $1 \mathrm{wt} \%$. In order to ensure a homogeneous viscous solution, high power mechanical stirring was used. After 60 min, the $\mathrm{SiO}_{2}$ nanoparticles were carefully added and continuously stirred for 24 hours. The composition of the obtained samples is presented in Table 1. 
Table 1. Sample concentrations

\begin{tabular}{|c|c|c|c|}
\hline \multirow{2}{*}{ Bis-GMA [\%] } & \multirow{2}{*}{ HEMA [\%] } & \multicolumn{2}{|c|}{ SiO2 nanoparticles } \\
\cline { 3 - 4 } & & Conc.[wt.\%] & Size [nm] \\
\hline \multirow{3}{*}{60} & \multirow{3}{*}{40} & 0 & 0 \\
\cline { 3 - 4 } & & \multirow{2}{*}{10} & 30 \\
\cline { 3 - 4 } & & & 100 \\
\cline { 3 - 4 } & & & 150 \\
\hline
\end{tabular}

Light curing of the resin was initiated through a $30 \mathrm{~min}$ irradiation with UV/Vis light by a $375 \mathrm{~W}$ mercury vapor lamp (L 6/58, Famed-1) in ISO standardized Teflon molds.

\subsection{Characterization}

The obtained Bis-GMA/HEMA - $\mathrm{SiO}_{2}$ biomaterials were tested for flexural strength (Fs), flexural modulus (Ey), work of fracture (EWF) and compressive strength (Cs) by using an Instron universal test machine (China-Made, Universal Testing Machine). Sample measurements $(\mathrm{l}=25 \mathrm{~mm}, \mathrm{w}=2 \mathrm{~mm}, \mathrm{~h}=2$ $\mathrm{mm}$ ) and test specifications were performed according to ISO 10477 and ISO 4049 standards.

The flexure strength was measured by charging in 4-point bending. The load applicator is not a single point source, it consists in two points divided by a well-prescribed width. The advantage of the 4-point technique is that it focuses the stress across a larger beam area, thus indicating that the beam can collapse in this region. To analyze the compression strength of the obtained composites, an axial force was applied to a cylindrical specimen at a constant strain rate, setting up tensile and shear stresses that cause failure inside the sample [25].

Mechanical properties were calculated by applying the following formulas:

Flexural strength (Fs):

Flexural modulus (Ey):

$$
F S=\frac{3 \cdot F \cdot l}{2 \cdot b \cdot h^{2}}
$$

$$
E y=\frac{l^{3} \cdot F_{1}}{4 \cdot f \cdot b \cdot h^{3}}
$$

Work of fracture (EWF):

$$
E W F=\frac{A}{b \cdot h}
$$

where:

- $\mathrm{F}$ - the applied load at highest point $(\mathrm{N})$;

- 1 - span length;

- $\mathrm{b}$ - test specimen width;

- $\mathrm{h}$ - test specimen thickness;

- $\mathrm{F}_{1}-$ load at a suitable point in the straight line portion of the trace $(\mathrm{N})$;

- $\mathrm{f}$ - test specimen deflection ( $\mathrm{mm}$ );

- A - the load applied to deflect and fracture the specimen (J) [26].

\section{Results and discussions}

Any dental restorative or prosthetic content, as well as natural teeth, must have adequate functional integrity to resist in the oral cavity for a long period of time, ideally throughout the patient's entire life. Therefore, the study of mechanical properties is extremely important.

One of the key threats of dental reconstruction is the formation and propagation of cracks and the potential failure of dental implants obtained from composite resins. The addition of nanoparticles to the resin to improve the mechanical strength of the composite is one of the methods of interest.

It is well established that Bis-GMA / HEMA polymers achieve a high crosslinking between monomers, one of the reasons is the fact that HEMA molecules are much smaller [27, 28], creating a 
good mobility of the Bis-GMA molecules to move in the nanocomposites. In addition to the neat sample, the addition of nanoparticles will only increase mechanical stability.

However, even in the nanoscale, there are still notable variations, with the majority being related to their size. Decreasing the particle diameter will lead to an increase in the active surface area, as depicted in Figure 1.

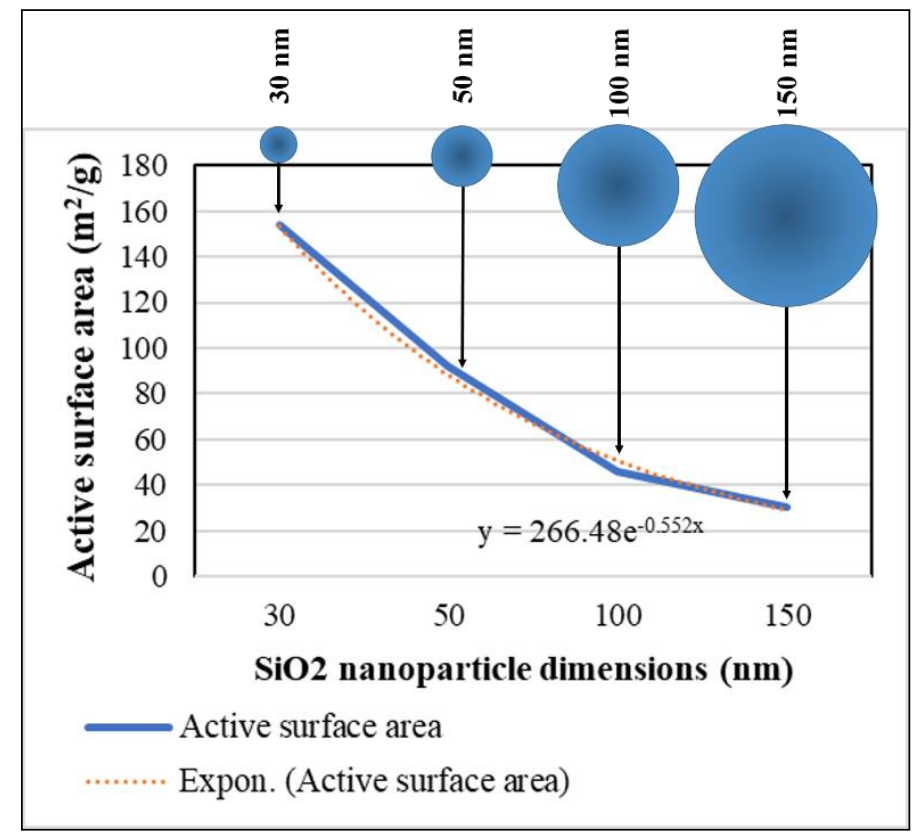

Figure 1. Graphical and schematic representation of correlation between nanoparticle size and active surface area

The active surface area was calculated based on $\mathrm{SiO}_{2}$ bulk density of $2.64 \mathrm{~g} \cdot \mathrm{cm}^{-3}$ and simple geometry equations. Of course, these values are theoretical and are extracted from the ideal shape of a nanoparticle, the sphere. A higher surface area of nanoparticles is understood as a larger number of connections with the polymer chains, which therefore will likely increase the mechanical properties of composite resins.

It is very important to take into account that nanoparticles can lead towards agglomeration under a certain nanometric size due to an enhanced collision energy between particles at the mixing step, which can cause significant defects in the matrix resin structure that can only be detected with a microscope.

Following the study of the mechanical strength of the samples obtained, it was observed that the addition of $\mathrm{SiO}_{2}$ nanoparticles significantly improved the flexural strength (Fs) of the resin composites compared to the Bis-GMA / HEMA blend, as it can be observed in Figure 2.

By decreasing the $\mathrm{SiO}_{2}$ nanoparticles dimension it was observant that the flexural strength is improved. Addition nanoparticles with a size of $150 \mathrm{~nm}$ show a decrease in mechanical properties due to the overcrowding of the fillings which brings a disadvantage in the resin matrix. 


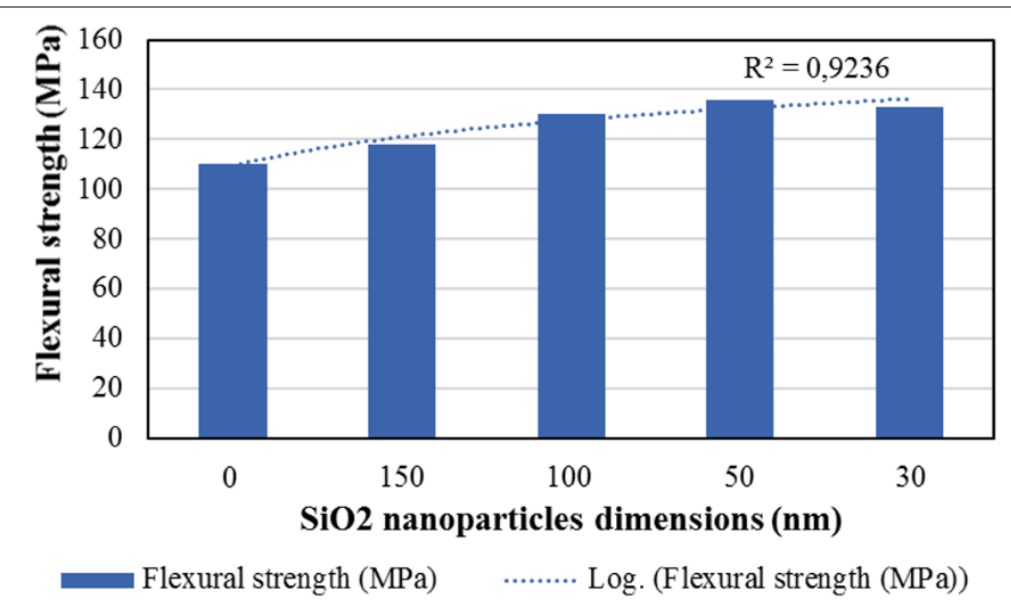

Figure 2. Flexural strength

All the composites showed stronger flexural properties with the addition of $\mathrm{SiO}_{2}$ nanoparticles than the neat resin (Figure 2 and 3). The flexural strength (Fs) and flexural modulus (Ey) of the composites was stronger when the $\mathrm{SiO}_{2}$ nanoparticles dimension was 50 and $100 \mathrm{~nm}$, reaching a peak value for the material with $50 \mathrm{~nm} \mathrm{SiO}_{2}$ nanoparticle.

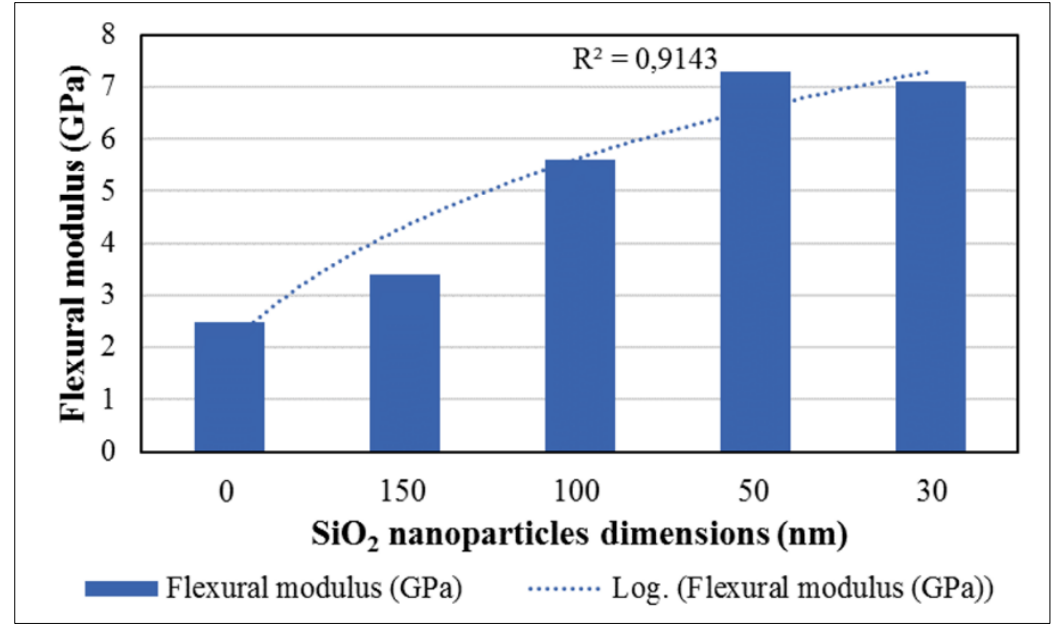

Figure 3. Flexural modulus

The flexural properties increased over $30 \%$ for the samples with $50 \mathrm{~nm}$ and $100 \mathrm{~nm} \mathrm{SiO} 2$ nanoparticle compared to the neat resin. At further increasing the nanoparticle size up to $150 \mathrm{~nm}$, the flexural strength (Fs) as well as the flexural modulus (Ey) values of the corresponding composites began to decrease.

Flexural stability is strongly related to the interaction between polymeric chains and nanoparticles. A lower nanoparticle size will lead to a higher number of phisical and chemical bonds with the polymer chains. This means that stress is uniformly distributed across the structure, and a more efficient transfer between matrix and filler is reached. On the other hand, increasing filler size will not cause a pronounced mechanical resistance, confirmed by the flexural properties of the $150 \mathrm{~nm} \mathrm{SiO} 2$ blended resin composite. However, for the sample with filler of $30 \mathrm{~nm}$ size, a slow decrease in flexural strength and modulus is observed. This could be a consequence of agglomeration tendency at very low nanoparticle dimensions, resulting in micro-defects in structure, which generate sample failure.

It is observed in Figure 4, that compressive strength was enhanced directly proportional to nanoparticle size, which is translated as a good binding strength due to filler addition. 


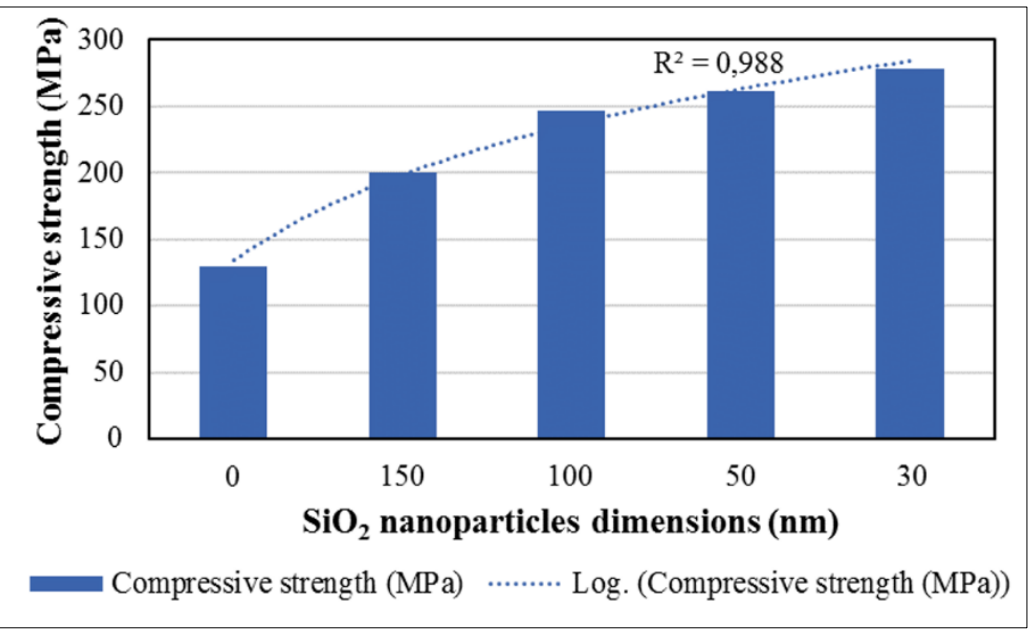

Figure 4. Compressive strength

In compressive state of the studied composite resins, nanoparticles play a different role. In the case of flexural tests, sample failure occurs in an area intentionally subjected to high stress due to opposite directions of the polymer chains movement. When discussing compression tests, mechanical stress occurs as a result of pressing polymer chains between them. Here the energy transfer between the polymer and the nanoparticle is higher and uniform throughout the structure of the material. The defects caused by the agglomeration of nanoparticles are not so obvious, because they are compacted as the load increases, which is why in the case of materials with the addition of $30 \mathrm{~nm}$ nanoparticles, the compressive strength is higher than in the case of other materials.

Since fracture is one of the key modes of failure for dental composites, this property is highly important to their characterization. Since most methods of obtaining materials do not offer the possibility of obtaining ideal structures, the application of specific charge allows the material to break due to structural defects. Thus the strength characteristics are reduced compared to those measured on ideal surfaces. The composites showed significant improvement in terms of work of fracture by increasing the $\mathrm{SiO}_{2}$ nanoparticles dimension to $50 \mathrm{~nm}$. Instead, due to the presence of structural defects, the fracture rezistance decreases at higher and lower nanoparticle sizes.

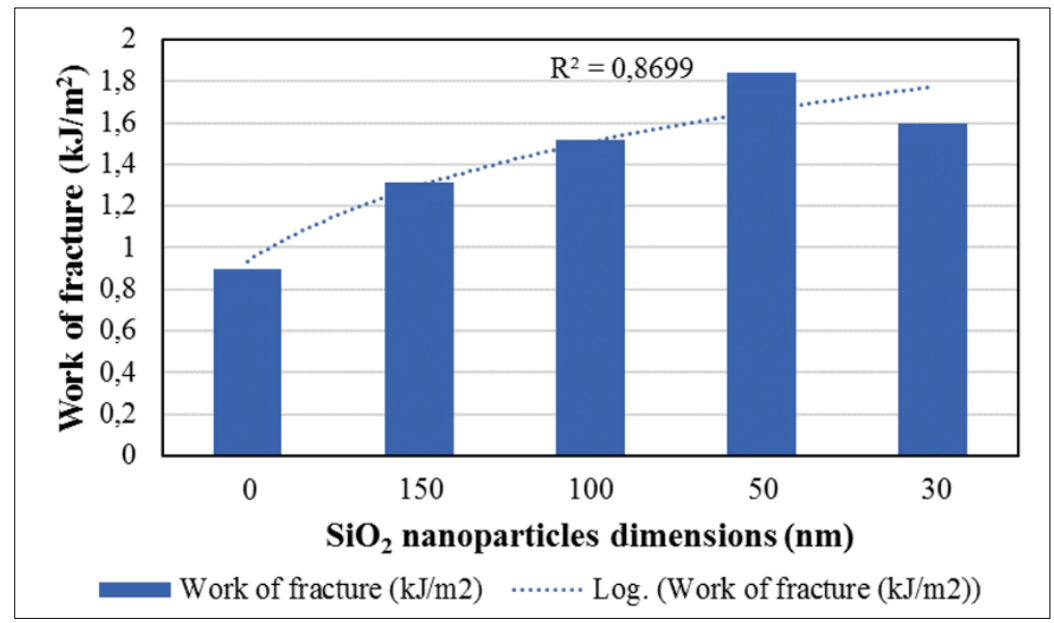

Figure 5. Work of fracture

The strong chemical bond between biomaterial and nanoparticles results in a uniform stress distribution and is able to minimize the occurrence of stress concentration, leading to a significant increase in the mechanical properties of the resulting composites . 


\section{Conclusions}

The study showed that the presence of silicon dioxide nanoparticles can significantly improve the properties of composite biomaterials compared to the control sample. The mechanical strength of resins with the addition of $\mathrm{SiO}_{2}$ nanoparticles has been improved, due to the strong chemical bond between the resin matrix and the nanoparticles. The greatest improvement in mechanical properties was observed in samples with the addition of $\mathrm{SiO}_{2}$ nanoparticles with a size of $50 \mathrm{~nm}$ in Bis-GMA / HEMA resin. By changing of $\mathrm{SiO}_{2}$ dimension above or below $50 \mathrm{~nm}$, the interface between the nanoparticles and the neat resins can restrict the enhancement of the mechanical properties of the composites, as observed in the case of $\mathrm{SiO}_{2}$ nanoparticles with $150 \mathrm{~nm}$ size or in the case of the $30 \mathrm{~nm}$ size particles, which could be linked to nanoparticle agglomeration.

\section{References}

1. THIAN, E., S., HUANG J., AHMAD, Z., EDIRISINGHE, M., J., JAYASINGHE, S., N., IRELAND, D., C., BROOKS, R., A., RUSHTON, N., BEST, S., M., BONFIELD, W., Influence of nanohydroxyapatite patterns deposited by electrohydrodynamic spraying on osteoblast response, $J$. Biomed Mater Res, 85A, 2008, 188-194, https://doi.org/10.1002/jbm.a.31564.

2. THIAN, E., S., HUANG, J., BARBER, Z., H., BEST, S., M., BONFIELD, W., Surface modification of magnetron-sputtered hydroxyapatite thin films via silicon substitution for orthopedic and dental applications, Surf. \& Coat. Techn. 205, 2011, 3472-3477, doi:10.1016/j.surfcoat.2010.12.012.

3. LAHANN, J., MITRAGOTRI, S., TRAN, T., N., KAIDO, H., SUNDARAM, J., CHOI, I., S., HOFFER, S., SOMORJAI, G, A., ANGER, R., A Reversibly Switching Surface, Science, 299, 2003, 371-374, doi: 10.1126/science.1078933.

4. CHEN, F., M., LIU, X., Advancing biomaterials of human origin for tissue engineering, Prog. Polym. Sci., 53, 2016, 86-168, doi: 10.1016/j.progpolymsci.2015.02.004.

5. LUNGU, M., MOLDOVAN, L., CRACIUNESCU, O., DOICIN, C., Biocompatible Blends Based on Polyvinyl Chloride and Natural Polymers for Medical Device Fabrication, Mater. Plast., 47(3), 2010, 278-281.

6. MORAIS, J., M., PAPADIMITRAKOPOUlOS, F., BURGESS, D., J., Biomaterials/Tissue Interactions: Possible Solutions to Overcome Foreign Body Response, AAPS J., 12(2), 2010, 188-196, DOI: $10.1208 / \mathrm{s} 12248-010-9175-3$.

7. PRIYADARSHINI, B., RAMA, M., CHETAN, VIJAYALAKSHMI, U., Bioactive coating as a surface modification technique for biocompatible metallic implants: a review, J. of Asian Ceramic Societies, 7(4), 2019, 397-406, https://doi.org/10.1080/21870764.2019.1669861.

8. DOUETTE, P., CHAUSSON, M., THEATRE, E., PHILIPPART, C., GAUTIER, S., BENTIN, J., HERMITTE, L., Biological Safety Evaluation of KiO medine CM-chitosan, an Innovative Non-animal Carboxymethyl-Chitosan Biomaterial Intended for Injectable Biomedical Applications, J. of Biomat., 4(2), 2020, 39-50, doi: 10.11648/j.jb.20200402.12.

9. MURARIU, A., DINU, C., AGOP FORNA, D., STEFANESCU, V., TOPOR, G., FORNA, N., C., FOTEA, S., GURAU, G., IORDACHE, C., Composite Resins - Multifunctional Restorative Material and Practical Approaches in Dental Field, Mater. Plast., 57(2), 2020, 276-284,

https://doi.org/10.37358/Mat.Plast.1964.

10.ROSHANALI, M., NODEHI, A., ATAI, M., Synthesis and characterization of core-shell nanoparticles and their application in dental resins, J. Mech. Beh. of Biomed. Mat., 110, 2020, 103926, https://doi.org/10.1016/j.jmbbm.2020.103926.

11.CANCHÉ-ESCAMILlA, G., DUARTE-ARANDA, S., TOLEDANO, M., Synthesis and characterization of hybrid silica/PMMA nanoparticles and their use as filler in dental composites, Mater. Sci. Eng. C, 42, 2014, 161-167, https://doi.org/10.1016/j.msec.2014.05.016.

12. SIDERIDOU, I., D., ACHILIAS, D., S., Elution Study of Unreacted Bis-GMA, TEGDMA, UDMA, and Bis-EMA from Light-Cured Dental Resins and Resin Composites Using HPLC, J. of Biomed. Mat. Researsch, Part B Applied Biomaterials, 74B (1), 2005, 617-626, https://doi.org/10.1002/jbm.b.30252. 
13. MOSZNER, N., ULRICH, S., New developments of polymeric dental composites, Prog Polym Sci, 26(4), 2001, 535-576, https://doi.org/10.1016/S0079-6700(01)00005-3.

14. PEUTZFELDT, A., Resin composites in dentistry: the monomer systems, Eur. J. Oral Sci, 105, 1997, 97-116, https://doi.org/10.1111/j.1600-0722.1997.tb00188.x.

15. CRAMER, N., B., STANSBURY, J., W., BOWMAN, C., N., Recent advances and developments in composite dental restorative materials, J. Dent. Res., 90, 2011, 402-416,

https://doi.org/10.1177/0022034510381263.

16. VAN LANDUYT, K., L., SNAUWAERT, J., DE MUNCK, J., PEUMANS, M., YOSHIDA, Y., POITEVIN, A., et al., Systematic review of the chemical composition of contemporary dental adhesives, Biomaterials, 28, 2007, 3757-3785, https://doi.org/10.1016/j.biomaterials.2007.04.044.

17. KRIFKA, S., SPAGNUOLO, G., SCHMALZ, G., SCHWEIKL, H., A review of adaptive mechanisms in cell responses towards oxidative stress caused by dental resin monomers, Biomaterials, 34(19), 2013, 4555-4563, https://doi.org/10.1016/j.biomaterials.2013.03.019.

18. FLOYD, C., J., E., DICKENS, S., H., Network structure of Bis-GMA- and UDMA-based resinsystems, Dental Materials, 22, 2006, 1143-1149, doi: 10.1016/j.dental.2005.10.009.

19.COELHO, C., C., ARAÚJO, R., QUADROS, P., A., SOUS, S., R., MONTEIRO, F., J., Antibacterial bone substitute of hydroxyapatite and magnesium oxide to prevent dental and orthopedic infections, Mat. Sci. \& Eng. C, 97, 2019, 529-538, https://doi.org/10.1016/j.msec.2018.12.059.

20.SUN, W., CAI, Q., LI, P., DENG, X., WEI, Y., XU, M., YANG, X., Post-draw PAN-PMMA nanofiber reinforced and toughened Bis-GMA dental restorative composite, Dental Materials, 26(9), 2010, 873-880, doi:10.1016/j.dental.2010.03.022.

21.PRATAP, B., GUPTA, R., K., BHARDWAJ, B., NAG, M., Resin based restorative dental materials: characteristics and future perspectives, Jpn Dent Sci Rev, 55(1), 2019, 126-138,

doi: 10.1016/j.jdsr.2019.09.004

22.ARCIS, R., W., LOPEZ-MACIPE, A., TOLEDANO, M., OSORIO, E., RODRIGUEZCLEMENTE, R., MURTRA, J., FANOVICH, M., A., PASCUAL, C., D., Mechanical properties of visible light-cured resins reinforced with hydroxyapatite for dental restoration, Dent Mater, 18, 2002, 49-57, doi: 10.1016/S0109-5641(01)00019-7.

23.LIU, F., JIANG, X., ZHANG, Q., ZHU, M., Strong and bioactive dental resin composite containing poly(Bis-GMA) grafted hydroxyapatite whiskers and silica nanoparticles, Comp. Sci. and Techn., 101, 2014, 86-89, https://doi.org/10.1016/j.compscitech.2014.07.001.

24.SUTTIPONPARNIT,K., JIANG, J., SAHU, M., SUVACHITTANONT, S., CHARINPANITKUL, T., BISWAS, P., Role of Surface Area, Primary Particle Size, and Crystal Phase on Titanium Dioxide Nanoparticle Dispersion Properties, Nanoscale Res Lett, 6, 2011, art. No. 27,

doi: $10.1007 / \mathrm{s} 11671-010-9772-1$

25.A.P.G. FRANCO, L.Z. KARAM, J.R. GALV AO, H.J. KALINOWSKI, Evaluation of shrinkage polymerization and temperature of different acrylic resins used to splinting transfer copings in indirect impression technique,24th International Conference on Optical Fibre Sensors, Vol. 9634 (2015), p. 96347R

26.S. LUO, W. ZHU, F. LIU, J. HE, Preparation of a Bis-GMA-Free dental resin system with synthesized fluorinated dimethacrylate monomers, Int J Mol Sci, 17 (12) (2016), 10.3390/ijms17122014 27.I. BARSZCZEWSKA-RYBAREK, S. JURCZYK, Comparative study of structure-property relationships in polymer networks based on bis-gma, tegdma and various urethane-dimethacrylates Materials, 8 (3) (2015), pp. 1230-1248, 10.3390/ma8031230

28.J. DURNER, K. SCHRICKEL, D.C. WATTS, N. ILIE, Determination of homologous distributions of Bis-EMA dimethacrylates in bulk-fill resin-composites by gc-ms, Dent Mater, 31 (4) (2015), pp. $473-480$

Manuscript received: 6.02 .2021 